UCRL-JC-130859

PREPRINT

\title{
Decommissioning Plan for the National Ignition Facility
}

\author{
S. Brereton, J. Latkowski, M. Singh, M. Tobin, J. Yatabe
}

This paper was prepared for submittal to the 1998 American Nuclear Society Annual Meeting

Nashville, TN

June 7-11, 1998

May 27, 1998

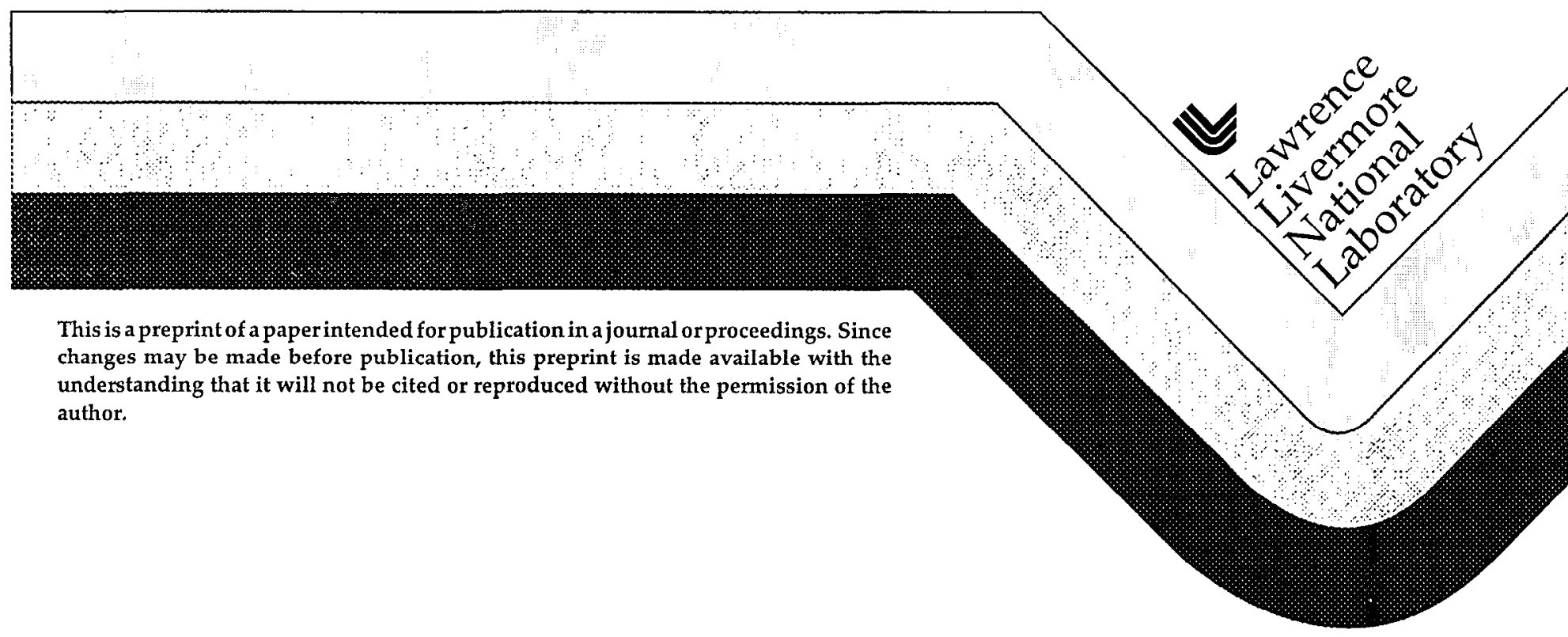




\section{DISCLAIMER}

This document was prepared as an account of work sponsored by an agency of the United States Government. Neither the United States Government nor the University of California nor any of their employees, makes any warranty, express or implied, or assumes any legal liability or responsibility for the accuracy, completeness, or usefulness of any information, apparatus, product, or process

disclosed, or represents that its use would not infringe privately owned rights. Reference herein to any specific commercial product, process, or service by trade name, trademark, manufacturer, or otherwise, does not necessarily constitute or imply its endorsement, recommendation, or favoring by the United States Government or the University of California. The views and opinions of authors expressed herein do not necessarily state or reflect those of the United States Government or the University of California, and shall not be used for advertising or product endorsement purposes. 


\title{
DECOMMISSIONING PLAN FOR THE NATIONAL IGNITION FACILITY
}

\author{
S. Brereton, J. Latkowski, M. Singh, M. Tobin, and J. Yatabe \\ Lawrence Livermore National Laboratory \\ P.O. Box 808, L-493, Livermore, CA, 94551
}

\begin{abstract}
The National Ignition Facility (NIF) is a U.S. Department of Energy inertial confinement laser fusion experimental facility currently under construction at the Lawrence Livermore National Laboratory (LLNL). To ensure that decontamination and decommis-sioning (D\&D) issues at the end-of-life are manageable, this subject has received attention from an early stage. This paper summarizes the NIF $D \& D$ issues, and the status of the D\&D plan.
\end{abstract}

\section{INTRODUCTION}

The NIF mission is to achieve inertial confinement fusion (ICF) ignition, access physical conditions in matter of interest to nuclear weapons physics, provide an above ground simulation capability for nuclear weapons effects testing, contribute to the development of inertial fusion for electrical power generation, and to support basic science and technology. To achieve this mission, the facility will require a $1.8 \mathrm{MJ}$ laser at $500 \mathrm{TW}$. 192 identical beamlets will be focused and directed onto a target suspended in the center of the spherical aluminum alloy target chamber. After ignition is achieved, approximately $25 \%$ of the 1200 annual experiments will involve tritium fuel and will actually achieve fusion yield, releasing neutrons, charged particles, $x$-rays, and debris. Unburned tritium will be exhausted from the target chamber to the tritium processing/ collection system. Fusion and secondary neutrons will activate the target chamber itself, the supporting structure for the target chamber, the concrete and rebar in the target bay walls, and the gases in the air. Consequently, some level of residual radioactivity will exist in some parts of the facility.

To better understand this issue, and to minimize its impact at end-of-life, the initial decommissioning plan was prepared for NIF.' The plan addressed the entire facility, including the laser, the target area, and auxiliary systems. We have updated the plan to match Title II design. The assessment was prepared to ensure that features and measures are incorporated into the NIF to facilitate the decontamination and decommissioning at the end of life. The minimum goal is to return the NIF to restricted DOE use. This paper summarizes the key features of the decommissioning plan.

\section{TARGET AREA DECOMMISSIONING}

\section{A. Assumptions}

Several assumptions about overall NIF facility operations are the basis for this assessment. The NIF will operate for 30 years, more than 10,000 laser experiments will be conducted, and a small portion of these will produce fusion yield, as shown in Table I.

After 2011, we assume NIF will continue at the level of $1200 \mathrm{MJ}$ per year. Table II shows the assumptions concerning the maximum annual number of shots, tritium throughputs, and yields for the remainder of the NIF lifetime. Note that all yield-

Table I. Assumed NIF tritium use and fusion yield performance during the first ten years of operation.

\begin{tabular}{|c|c|c|c|c|c|}
\hline $\begin{array}{c}\text { End } \\
\text { of } \\
\text { fiscal } \\
\text { year }\end{array}$ & $\begin{array}{c}\text { D-T } \\
\text { shots }\end{array}$ & $\begin{array}{c}\text { Ci } \\
\text { per } \\
\text { shot }\end{array}$ & $\begin{array}{c}\text { Total } \\
\text { Ci }\end{array}$ & $\begin{array}{c}\text { Yield } \\
\text { per } \\
\text { shot } \\
\text { (MJ) }\end{array}$ & $\begin{array}{c}\text { Total } \\
\text { yield } \\
\text { (MJ) }\end{array}$ \\
\hline 2001 & 0 & 0 & 0 & 0 & 0 \\
\hline 2002 & 5 & 0.02 & 0.1 & $<0.001$ & $<0.005$ \\
\hline 2003 & 5 & 0.02 & 0.1 & $<0.001$ & $<0.005$ \\
\hline 2004 & 10 & 0.5 & 5 & $<0.001$ & $<0.005$ \\
\hline 2005 & 70 & 1.5 & 105 & 0.01 & 0.7 \\
\hline 2006 & 250 & 1.5 & 375 & 0.1 & 25 \\
\hline 2007 & 250 & 1.5 & 375 & 0.2 & 50 \\
\hline 2008 & 280 & 1.5 & 420 & $\leq 5.0$ & 200 \\
\hline 2009 & $>300$ & 1.5 & $>450$ & $\leq 20$ & 500 \\
\hline 2010 & $>300$ & 1.5 & $>450$ & $\leq 20$ & 1025 \\
\hline 2011 & $>300$ & 1.5 & $>450$ & $\leq 20$ & 1200 \\
\hline
\end{tabular}

\footnotetext{
Work performed under the auspices of the U.S. Department of Energy by Lawrence Livermore National Laboratory under Contract W-7405-Eng-48.
} 
Table II. Assumed D-T experiments during NIF lifetime, with phased achievement of ignition and gain.

\begin{tabular}{|l|c|c|c|c|c|c||}
\hline \hline Experiment type (yield) & $\begin{array}{c}\text { Annual } \\
\text { D-T shots }\end{array}$ & $\begin{array}{c}\text { Lifetime } \\
\text { D-T shots }\end{array}$ & $\begin{array}{c}\text { Annual } \\
\text { tritium Cib }\end{array}$ & $\begin{array}{c}\text { 20-year } \\
\text { tritium Ci }\end{array}$ & $\begin{array}{c}\text { Annual fusion } \\
\text { yield (MJ) }\end{array}$ & $\begin{array}{c}\text { 20-year } \\
\text { fusion } \\
\text { yield (MJ) }\end{array}$ \\
\hline Indirect drive (20 MJ) & 25 & 500 & 37.5 & 1125 & 500 & 15,000 \\
\hline Indirect drive (5 MJ) & 20 & 400 & 30 & 900 & 100 & 3000 \\
\hline Indirect drive (0.1 MJ) & 200 & 4000 & 300 & 9000 & 20 & 600 \\
\hline Direct drive (20 MJ) & 25 & 500 & 375 & 11,250 & 500 & 15,000 \\
\hline Direct drive (5 MJ) & 15 & 300 & 225 & 6750 & 75 & 2250 \\
\hline Direct drive (0.1 MJ) & 50 & 1000 & 750 & 22,500 & 5 & 150 \\
\hline \hline Subtotal & 335 & 6700 & $1750^{c}$ & 35,000 & 1200 & 24,000 \\
\hline \hline Totals from first 10 yrd & & 1775 & & 2640 & & 3000 \\
\hline \hline NIF Lifetime Total & & 8475 & & 37,640 & & 27,000 \\
\hline
\end{tabular}

aThe maximum credible yield [for accident analyses] is $45 \mathrm{MJ}$.

'Tritium annual total rounded up to $1750 \mathrm{Ci}$.

b Tritium content per indirect drive target is $1.5 \mathrm{Ci}$ (15 Ci for direct drive). ${ }^{\mathrm{d}}$ Assumes only indirect drive during this time.

producing shots employ cryogenic targets and deuterium-tritium (D-T) fuel contained in small capsules within the indirect-drive (or direct-drive) targets. Direct-drive fusion is not a basic capability of the NIF; however, the capability is not precluded by the NIF design. Direct-drive operations, if implemented, are assumed to begin after 10 years of NIF operation. Direct-drive targets contain $15 \mathrm{Ci}$ of tritium, compared to $1.5 \mathrm{Ci}$ in indirect-drive targets.

Two radiological issues dominate decommissioning at the end-of-life: the extent of tritium contamination, and the contact dose rate due to long-lived activation products induced in components and large structures. Some facility features will minimize these issues at the end-of-life:

- confinement barriers and ventilation control will prevent or minimize the spread of tritium throughout the facility,

- special surface coatings, such as the use of epoxy paints on walls, ceilings, and floors will provide an effective barrier against tritium sorption,

- use of low activation materials.

Operational procedures will also minimize the extent of contamination, for example: components removed from the target chamber will be properly packaged, and personal protective equipment will be used in contaminated areas. Experimenters will be instructed to minimize the total target mass and to carefully select target materials. In addition, periodic cleaning of equipment exposed to tritium and activated debris will maintain low contamination levels throughout the facility lifetime. These practices will significantly reduce, if not virtually eliminate, the need for major end-of-life decontamination. Cleaning and decontamination technologies have been developed to meet NIF decontamination needs. Cleaning methods are likely to include:

- vacuum bake-out, water rinse, dilute acid wash for debris shields,

- high pressure water spray, ultra-sonic bath in water and surfactants, oven dry for first wall panels,

- aqueous wipe-down of small diagnostics,

- $\mathrm{CO}_{2}$ snow cleaning for large diagnostics with complex geometries.

NIF decommissioning operations will make every effort to reuse and recycle all portions of the target area. We assume that a tritium contamination level less than $100 \mathrm{dpm} / \mathrm{cm}^{2}$ of removable or fixed tritium $^{2}$ will allow material to go to uncontrolled reuse or to conventional disposal (scrap yard). We also assume a contact dose rate level that will allow material with induced radioactivity to go to uncontrolled reuse. This level is defined as follows: the contact dose rate that results in a TEDE to the average member of the critical group not exceeding $25 \mathrm{mrem} / \mathrm{yr}^{3}$ For estimating purposes, we conservatively assume 2000 hours per year of exposure, and the contact dose rate of interest becomes $\leq 0.0125 \mathrm{mrem} / \mathrm{hr}$ above background. Activated material above these levels would be held in storage at the NIF site until disposed of as 
radioactive waste or transferred to controlled reuse. We further assume that semi-permanent facility features that contain materials of concern for neutron activation, such as cable runs and diagnostics, will be maintained such that contact dose rates will support their reuse in other facilities, or they will be disposed of as operational waste prior to reaching an activation level of concern. This will be achieved through a combination of periodic change-out, radioactive decay time, and shielding.

\section{B. Neutron Activated Wastes}

Residual dose rates have been calculated for NIF Target Bay components. During decommissioning of the facility, workers would receive an effective dose that would depend upon the radiation intensity from components and the time required for disassembly of each component. Table III gives the residual dose rates from major components at 30 days and 3 years following 30 years of NIF Expanded Baseline (1200 $\mathrm{MJ} /$ year) operation. These dose rates are used in conjunction with estimates of the time required to decommission each component to determine the dose that would be received.

Table III lists components in approximate order of removal. Some credit has been taken for the removal of key components. For example, the final optics assemblies make significant contributions to the residual dose rates in many areas of the NIF Target Bay. Once they are removed, however, subsequent doses do not include their contribution.
We have assumed that the delicate components, such as final optics assemblies and diagnostics, would be removed early in the process before "dirty" processes are begun. The target chamber and gunite shielding, for example, must be removed prior to the removal of the pedestal. Considering these factors, we have taken credit for the fact that some components will not be present when others are being removed.

\section{Tritium Contaminated Wastes}

At the end-of-life, components exposed to tritium throughout NIF operations, will be tritium contaminated. This includes the target chamber and first wall, vacuum system, the tritium processing system, and the decontamination area gloveboxes/ hoods. Tritium is not anticipated to be a significant contaminant in the structures outside the chamber, such as the concrete walls, floors, and support structures. The average surface concentration of tritium in walls and floors after NIF decommissioning is expected to be be $<100 \mathrm{dpm} / \mathrm{cm}^{2}$.

We do not yet have good predictive capability for estimating tritium contamination levels. However, our measurements on Nova indicate that $\geq 99 \%$ of the tritium not consumed in shots is removed through the vacuum system. A small amount is expected to diffuse into the chamber itself or be deposited at some depth due to ion implantation we estimate this quantity to be $\leq 10$ $100 \mathrm{Ci}$. In addition to the cleaning methods noted earlier, first wall surface ablation as a result of shots will release some fraction of the deposited tritium.

Table III. Residual dose rates from major components at 30 days and 3 years following NIF operation.

\begin{tabular}{|l|c|c|}
\hline \multicolumn{1}{|c|}{ Component being removed } & \multicolumn{2}{c|}{ Dose equivalent rate during removal (mrem/hr) } \\
30 days after shutdown & 3 years after shutdown \\
\hline \hline Diagnostics & 0.26 & 0.04 \\
\hline Target positioner & 1.0 & 0.25 \\
\hline Diagnostic manipulators & 0.23 & 0.06 \\
\hline Final optics assemblies & 1.1 & 0.15 \\
\hline Mirrors and enclosures* & 0.23 & 0.03 \\
\hline Mirror support structures & 0.34 & 0.04 \\
\hline First wall and beam dumps* & 0.63 & 0.13 \\
\hline Beamtubes & 0.30 & 0.06 \\
\hline Cable trays and cables & 0.37 & 0.06 \\
\hline Vacuum system & 1.0 & 0.13 \\
\hline Tritium processing system & 0.51 & 0.07 \\
\hline Gunite shielding & 1.3 & 0.13 \\
\hline Aluminum target chamber & 5.9 & 0.55 \\
\hline Target chamber cup and pedestal & 0.87 & 0.09 \\
\hline Catwalks and gratings & 0.17 & 0.02 \\
\hline Utilities and auxiliary systems & 0.25 & 0.03 \\
\hline Concrete (average) & 0.07 & 0.003 \\
\hline
\end{tabular}

* Dose rates are averaged over several individual tasks. 
Table IV. Labor requirements and occupational doses for decommissioning of the NIF Target Bay.

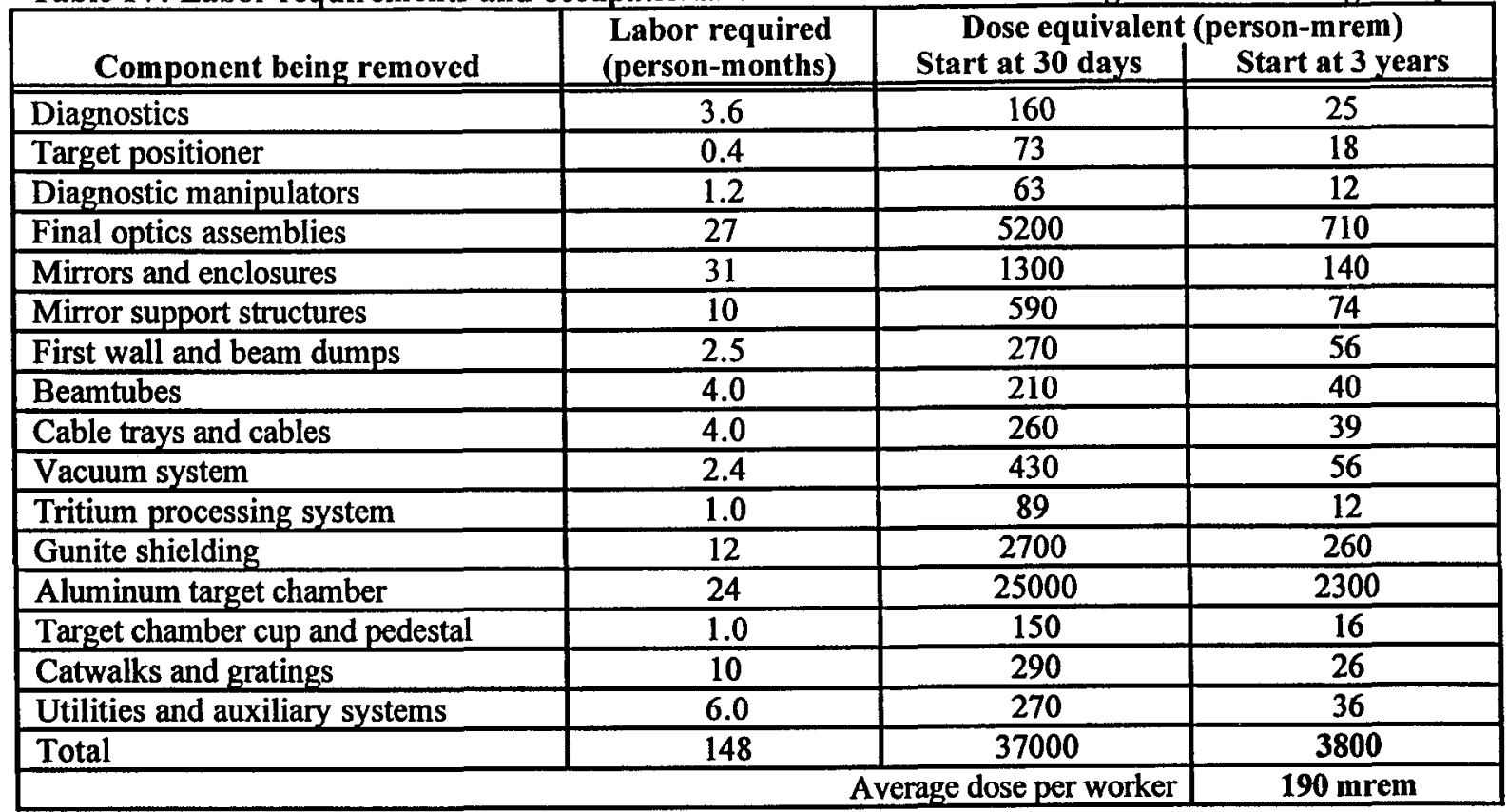

At end-of-life, residual tritium removal from the target chamber, first wall, vacuum system, tritium processing system, and decontamination gloveboxes/ hoods can be accomplished through a combination of the cleaning techniques identified earlier. In addition, pump down of the chamber using warm, moist air may aid in removing tritium from the target chamber. Thus, tritium levels in components are expected to be low, and a significant tritium decontamination effort at end-of-life is not expected.

\section{Worker Dose During Decommissioning}

Estimates have been made of the time required to decommission each of the key systems within the NIF Target Bay. We assume that a team of 20 workers is employed. The dose rate and the duration for each task are used to determine the total occupational dose and the average dose per worker. Table IV gives these estimates.

The duration for the removal of each component has been estimated starting from the estimates of the time required for initial assembly and/or installation of the component. In general, it is reasonable to expect that disassembly can be expected to require less manpower. The target chamber, for example, will be cut into pieces using a plasma torch. This process is inherently quicker than the exacting precision required for the initial target chamber assembly and installation. Where appropriate, the duration includes time required for additional handling associated with packaging of the component.
If the task of decommissioning the NIF were to begin only 30 days after the cessation of operations, the total occupational dose would be unacceptably high at 37 person-rem. If, however, decommissioning does not begin until 3 years after the final yield experiment, the total dose would be only about 4 person-rem. Based upon these results, it is recommended that decommissioning of the major components begin no earlier than 3 years after operation cease. (Note that this is based upon an assumed operation of 30 years at $1200 \mathrm{MJ} / \mathrm{year}$.) In this case, the average decommissioning worker would receive a dose of about $190 \mathrm{mrem}$.

Our occupational doses are conservative as we have assumed that workers are in close proximity to the component of interest during the entire 40-hour work week. In addition, we have neglected radioactive decay during decommissioning. Table IV estimates the total effort required at about 148 personmonths. For a crew of 20 workers, this suggests that the entire process would take less than 8 months. Since most doses are dominated by the decay of ${ }^{54} \mathrm{Mn}$, which has a half-life of 312 days, the final dose rates only would be about $60 \%$ of the initial levels.

\section{E. Comparison to Other Facility Wastes}

Radioactivity induced in beam transport systems and structural materials experienced at major particle accelerators used in medicine, basic research, and industry in many respects is comparable to that projected for the NIF. Although a number of the major accelerators, such as the 
Bevalac at LBL, have been shutdown during the past decade, there is very little documentation on decontamination or dismantling plans for these facilities. On the other hand, there is a substantial amount of information on decommissioning of research and commercial nuclear power plants. Cost to decommission a reactor is about $\$ 200 \mathrm{M}$. Reactors undergoing decommissioning show no correlation between waste amounts and power capacities. ${ }^{4}$ Radioactive waste per reactor is about 20,000 tonnes. The amount of work needed to decommission a plant, for instance the Loviisa Power Plant in Finland, is about 2900 personyears. $^{5}$ And the dose to workers for decommissioning such a plant would be 2300 person-rems. The dose to workers for decommissioning the NIF target bay in comparison is less than $0.2 \%$ of this value. The estimated quantity of NIF target bay waste is less than 1,000 tonnes. Non-reactor facilities such as the uranium enrichment plants and Y-12 Plant will generate substantial amount of waste, over a million $\mathrm{kg}$ of chemically contaminated building materials and equipment. Decommissioning of these facilities will cost in the billions. The cost estimate to decommission NIF is less than $\$ 30 \mathrm{M}$.

\section{DECOMMISSIONING THE NIF LASER}

At the end-of-life, the NIF laser and associated equipment will be removed from the facility. Many of the specialty components, such as the amplifier assemblies, some of the mirrors, spatial filters, optical pulse generation system, and beam control/laser diagnostics will be packaged and stored, until needed by some other current or future project. Other items, such as laser support systems, interstage beam transport system, control systems, and cabling will be salvaged.

One hazardous waste stream derived from the laser system will be from the oil filled capacitors. The oil is considered hazardous waste. Approximately $310 \mathrm{~m}^{3}(660 \mathrm{~kg})$ of oil would require disposal as hazardous waste at the end-of-life.

\section{TECHNICAL UNCERTAINTIES AND FUTURE WORK}

\section{A. Experimental Validation of Activation}

Calculation of neutron activities and residual dose equivalent rates requires use of neutron transport, neutron activation, and photon transport models. Each of these models may introduce uncertainties into the overall results, and thus, it is important to consider the overall uncertainty and, where possible, obtain experimental validation of the computer codes and data. During recent experiments at the Rotating Target Neutron Source (RTNS-I) at the University of California at Berkeley, samples of low-activation concrete, which will be used in selected locations within the NIF Target Bay, were irradiated and the residual dose rates were measured. ${ }^{6}$ Although the experiments concentrated on the shortlived radionuclides, which will dominate occupational dose rates during routine operations, the results validate the computer code system and several of the cross sections (for production of ${ }^{24} \mathrm{Na},{ }^{27} \mathrm{Mg}$, and ${ }^{36} \mathrm{Mn}$ ). Figure 1 shows the measured and predicted exposure rates for the irradiation of lowactivation concrete.

During decommissioning of the NIF, occupational dose rates will be dominated by ${ }^{54} \mathrm{Mn}\left(\mathrm{t}_{1 / 2}=\right.$ 312 days), ${ }^{60} \mathrm{Co}\left(\mathrm{t}_{1 / 2}=5.27\right.$ years), and ${ }^{65} \mathrm{Zn}\left(\mathrm{t}_{1 / 2}=\right.$ 244 days). Future RTNS-I experiments will validate the cross sectional data for the production of these radionuclides in the 5083 alloy of aluminum. Cross sections for the key reactions, however, are well known, and thus, good agreement with calculations is expected. Uncertainties in the calculated residual dose rates are expected to be less than $30 \%$.

\section{B. Uncertainty with Shot Schedule}

Residual dose rates have been calculated for 30 years of NIF operation and an annual yield of $1200 \mathrm{MJ} /$ year. While the actual annual yields may vary, $1200 \mathrm{MJ} /$ year will be the maximum allowable. Thus, the dose rates presented are for the bounding case.

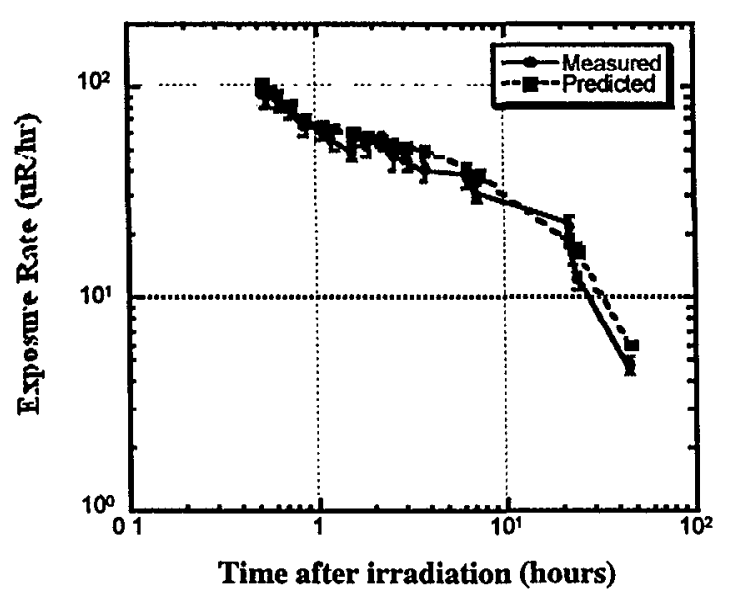

Figure 1. Excellent agreement has been obtained between measured and predicted exposure rates in the irradiation of low-activation concrete. 


\section{Decontamination efficiency}

A number of decontamination techniques have been considered for routine and end-of-life cleaning of NIF components. Early on, $\mathrm{CO}_{2}$ pellet cleaning was considered the prime method. However, testing found that this technique was ineffective for removing metal deposits from some of the more fragile objects (e.g., debris shields). $\mathrm{CO}_{2}$ cleaning is still planned for use, however, for some other components, such as diagnostics. Bead blasting was considered for first wall cleaning, where small metal pellets impinge upon the surface to be cleaned. This was abandoned for first wall cleaning because it was found to warp the first wall panels. More recently, simpler techniques have received more attention. For example, the use of vacuum bake-out, water rinse, and dilute acid wash for debris shields, and high pressure water spray, ultrasonic bath and oven drying for first wall panels. The effectiveness of these techniques at removing contamination will be evaluated in the near future.

\section{Confidence in volume/mass estimates}

Lifetime estimates have been made for various components and systems that will operate within the NIF Target Bay. Using these estimates, specific and total activities have been calculated for each waste stream. If actual material lifetimes are different from those estimated for this work, then the quantity of radioactive materials may increase or decrease. While the quantity and specific activity of material may change, the total activity is a conserved quantity. For example, if a particular component has an estimated lifetime of 10 years, then three components will be required during the 30-year facility lifetime. If these components each contain $1 \mu \mathrm{Ci}$ of activity at the end of their lifetime, then the total activity will be $3 \mu \mathrm{Ci}$. If, however, the actual lifetime is 15 years, then only two components will be required. Due to their longer lifetime, they will each contain $1.5 \mu \mathrm{Ci}$ at the end of their lifetime. This results in $50 \%$ less waste by volume, but the specific activity of the waste will be $50 \%$ greater. The total activity of the waste would remain constant at $3 \mu \mathrm{Ci}$.

\section{E. Tritium behavior}

There is uncertainty in the tritium contamination levels expected for various components at the end of NIF's operating life. We are in the process of developing a tritium tracking "model" to provide insight in this area. This tritium predictive capability will calculate "realistic" steady-state tritium quantitites for components that could be tritium sinks. As we develop this model, we will work towards a better understanding of some of the phenomena involved, e.g., the behavior of highly energetic tritons as they impact the first wall and debris shields. The model will allow us to perform "what if" calculations to assess the impacts of different operating modes on tritium management and safety. In addition, it will estimate end-of-life tritium inventories and be useful for predicting decontamination needs. The model is currently in a very early stage of development and takes the form of a spreadsheet. We plan to have a useful model available over the next several months.

\section{SUMMARY AND CONCLUSIONS}

NIF D\&D issues have be considered from an early stage in the design. Features, such as low activation materials, confinement barriers, ventilation control, and use of protective coatings, will facilitate decontamination and decommissioning at the end-of-life. Periodic cleaning of components throughout the lifetime will minimize end-of-life contamination levels. In addition, operating procedures will be developed to minimize the spread of contamination. Based on the current understanding and analysis, decommissioning the NIF will not present any major difficulties. It should be possible to return the facility to unrestricted use.

\section{REFERENCES}

1. M.T. Tobin et al., "NIF Decommissioning Plan", NIF-0001670, March 1997.

2. U.S Department of Energy, Radiological Control Manual, DOE N 5480.6, Table 2-2, June 1992.

3. U.S. Code of Federal Regulations 10CFR20.1402 Radiological Criteria for Unrestricted Use.

4. J. Vira and M. Yasui, "International Comparisons of Decommissioning Cost Estimates: Reasons for Discrepancies," in Decommissioning Policies for Nuclear Facilities, Proceedings of an International Seminar, Paris, Oct. 2-4, 1991.

5. T. Kukkola, "Decommissiong Cost Estimate of Loviisa Power Plant," in Decommissioning Policies for Nuclear Facilities, Proceedings of an International Seminar, Paris, Oct. 2-4, 1991.

6. A. P. Belian, J. F. Latkowski, and E. C. Morse, "Experimental Studies of Concrete Activation at the National Ignition Facility Using the Rotating Target Neutron Source," presented at the 17th IEEE/NPSS Symposium on Fusion Engineering, San Diego, October 610, 1997. 


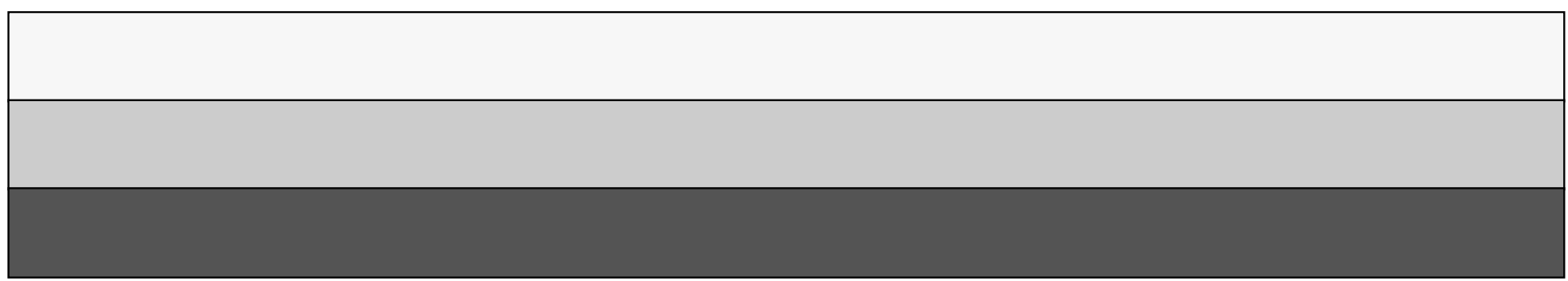

